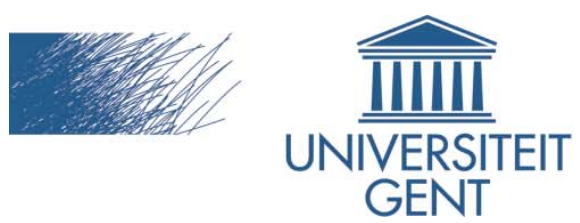

biblio.ugent.be

The UGent Institutional Repository is the electronic archiving and dissemination platform for all UGent research publications. Ghent University has implemented a mandate stipulating that all academic publications of UGent researchers should be deposited and archived in this repository. Except for items where current copyright restrictions apply, these papers are available in Open Access.

This item is the archived peer-reviewed author-version of:

The added value of organic farming for environment and health: facts and consumer perceptions Van Huylenbroeck, G.; Mondelaers, K., Aertsens, J.

In: British Food Journal, 111 (10), 1021-1027, 2009.

To refer to or to cite this work, please use the citation to the published version:

Van Huylenbroeck, G.; Mondelaers, K., Aertsens, J. (2009). The added value of organic farming for environment and health: facts and consumer perceptions. British Food Journal 111 (10), 1021-1027. 


\title{
The added value of organic farming for environment and health: facts and consumer perceptions
}

\author{
Published as... \\ Van Huylenbroeck, G.; Mondelaers, K., Aertsens, J.; 2009; "The added value of organic \\ farming for environment and health: facts and consumer perceptions"; \\ British Food Journal; Volume: 111 (10); pp. 1021-27;
}

\section{Introduction}

This special issue reports the results of a major research project ordered by the Flemish government on the real and perceived effects of organic farming for environment and health. Although a lot of scientific research is available on this topic, this research is often fragmented and published in different journals. Therefore the researchers have collected existing evidence, in particular on organic vegetable production, and systematically analyzed these data using meta-analytical statistical techniques. The objective was to assess in how far the present peer reviewed evidence allows hard conclusions with respect to the difference between conventional and organic produced food. These results were complemented with a major consumer survey among 529 households to analyze in how far perceptions and arguments used by consumers correlate with the found published results on possible differences with conventional products. The results are presented in this special issue because the researchers are convinced that this comprehensive review of existing evidence on both environmental and health differences, combined with evidence on consumer perception may give interesting clues for further optimizing the organic production method and for the marketing of organic products.

This introductory paper explains the focus of the issue, the general methodology followed in the research project and the main overarching findings.

\section{Focus of the research}

In the research project four major parts were distinguished. The coherence between these parts is presented in figure 1 below. In a first part the differences in environmental impact between conventional and organic production were analyzed through on the one hand a metaanalysis of the published evidence on environmental differences and on the other a life cycle impact comparison based on results of conventional and organic leek production. The second research part focused on the possible positive impact of organic production on nutrient intake and health. This part of the study has also been based on a statistical analysis of peer reviewed evidence. The third part focused on risk and food safety differences between conventional and organic food production and consumption, again based on scientific meta-analytical evidence with respect to differences in contaminant contents of vegetables produced according to both systems. Finally the fourth part compared consumer perception with the scientific evidence. This part is mainly based on a consumer survey conducted in Flanders in January 2007 with respondents ranging from highly involved organic consumers (heavy users) over medium and occasional users to non-users of organic produce. Besides insight in the perception of consumers, this survey also contained a choice experiment to derive the quality traits influencing the purchase decision of the different groups of organic consumers as well as 
questions allowing to analyze possible barriers in the purchase of organic products. In the six papers of this special issue, the results of these different analyses are reported.

Figure 1: Coherence of the different parts in the research project

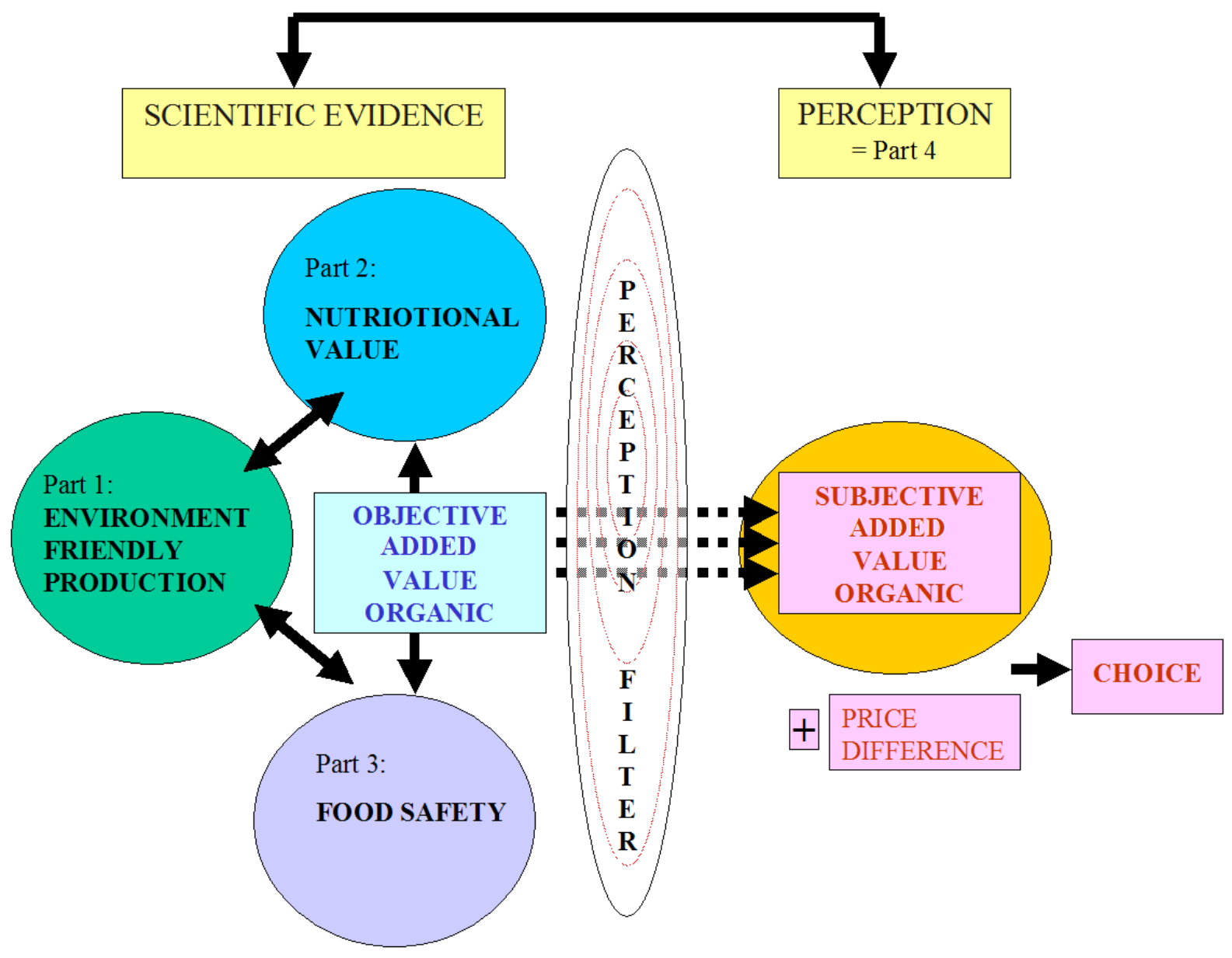

For a correct interpretation of the results presented, the following delimiting factors of the research have to be taken into account:

* The empirical evidence concerning environmental and nutritional differences is only based on recent publications in scientific journals. This means that the references taken into account satisfy following criteria: (i) peer reviewed; (ii) studies dating from after 1992 (year of EEC regulation 2092/91 on organic production standardizing the production method); and (iii) in the case of the meta-analysis related to the environmental impact of both farming systems only (semi) paired samples were used, meaning that organic and conventional data are compared within the same study using the same methodology.

* The research on nutritional and toxicological differences between organic and conventional produce is limited to analytical differences. It is hypothesized that such differences give a good basis for the possible impact on human health. Other possibilities to investigate the impact on human health such as epidemiological observation studies, intervention studies on animals and humans or in vitro studies are so far limited and thus have not been taken into account.

* For the same reason we also have not included in the reference data base studies that use so called 'holistic' analytical methods studying the differences in e.g. 
crystallographic structure of conventional and organic produced food products. These methods are still in an experimental stadium and their results have not yet been published in scientific journals.

* Another limitation is that the research has mainly focused on vegetable production and consumption because of following reasons: (i) vegetable products form a very important category in the organic market globally and are cultivated by the majority (75 percent) of the organic farmers in Flanders, (ii) for consumers fruit and vegetables are the main entry point into the organic market (Organic Centre Wales, 2004; Padel and Foster, 2005), (iii) vegetables form a major contribution in a healthy food consumption pattern, (iv) the research groups involved have major expertise in organic vegetable production and consumption.

* Finally, while the scientific evidence is based on international literature, the consumer survey has only be conducted in Flanders using a purposive sample with an overrepresentation of heavy and medium users of organic products. This procedure was chosen to compare differences in perceptions, attitude and behavior among groups with a different consumption pattern of organic products. This objective was reached by distributing a considerable amount of questionnaires among the members of VELT, a consumer organization promoting environment-friendly agriculture and an ecological lifestyle.

\section{Structure of the special issue}

The first article by Mondelaers et al. (2009a) presents the result of the meta-analysis of the scientific literature with respect to differences in environmental impact between conventional and organic farming. Based on an analysis of the results of more than 70 references, the difference in impact on land use efficiency, organic matter content of the soil, nitrate and phosphorous leaching, biodiversity and greenhouse gas emissions are analyzed and related to differences in the management practices between organic and conventional farming. A major point of attention is that the results obtained are highly dependent on whether they are expressed per area unit or per unit of product harvested. For most of the criteria investigated, organic production scores better than conventional production if expressed per area unit, but, as revealed by the meta-analysis of land use efficiency, organic production in developed countries results on average in a 17 percent decrease in yields. This implies less significant differences in environmental impacts between organic and conventional production when expressed per unit harvested product. Both results are interesting because they reflect the difference between the strong and weak view on sustainability ${ }^{1}$.

The meta-analysis of environmental effects is complemented in the second article with a Life Cycle Assessment (LCA) of organic and conventionally produced leek, combining data from the literature with data provided by Flemish research institutes. Using LCA, De Backer et al. (2009) also find that the results are different depending on whether the effects are expressed on area or on yield basis. Both results are relevant as the objective of an LCA is mainly to indicate for each system which environmental problems exist and to identify possibilities for

\footnotetext{
${ }^{1}$ Weak sustainability implies that all forms of capital are substitutable by each other so that any loss in one kind of capital can in theory be substituted by a surplus in other forms of capital. Critics claim that at least some forms of capital have no substitutes or require a certain critical level which cannot be substituted. The belief in non-substitutability of at least some kind of capital and, therefore, the need to conserve critical non substitutable stocks are central features of strong sustainability (Figge and Hahn, 2004).
} 
improvement. In this sense the article also identifies where organic production can still improve (e.g. by increasing the productivity of the system). The results presented for leek can of course not be generalized but do give interesting clues for further investigation and application of the LCA methodology. One limitation to be mentioned is that the reported LCA only covers the production stage and does not include differences in the transformation, distribution or consumption stages.

In the third article Hoefkens et al. (2009a) review the literature on the differences in nutrient and contaminant content between organic and conventional produced vegetables and potatoes. In total, 74 relevant publications were identified and included in the meta-analysis - 39 for nutrients and 35 for contaminants. The results are not conclusive but provide evidence that organically grown vegetables contain significantly lower concentrations of synthetic pesticide residues. The study does not allow to conclude that organic farming results in higher nutritional values or in significant reductions of microbiological risks compared to conventionally grown vegetables. This may result from the fact that nutrient and contaminant content of vegetables is depending on numerous other factors such as growing conditions, soil type, fertilisation, post-harvest storage, vegetable characteristics (variety, magnitude, ripeness) and their interaction, making conclusive results difficult. The large-scale metaanalysis does therefore not support the use of nutritional claims on organic vegetables and potatoes. However evidence from our survey indicates that regular consumers of organic products may have a more healthy lifestyle as they consume more fruits and vegetables, a factor which is proven to have beneficial health effects.

The fourth article by Aertsens et al. (2009) analyzes the literature describing how organic food purchase and consumption is influenced by personal determinants like values, beliefs, attitudes, emotions, norms, motivations and barriers. This paper shows that Values Theory and Theory of Planned Behaviour are theoretical frameworks allowing to understand organic food consumption. The review indicates that health, related to the value "security", is the strongest argument for purchasing organic food. Also taste, related to the value "hedonism", and the value "universalism" can play an important role in determining organic food purchases. It is relevant to note that significant differences seem to exist between consumer segments, e.g. for more regular consumers protection of the environment and nature and animal welfare seem to play a more important role. Aertsens et al. (2009) also found that relatively little research has examined the affective component of attitude and emotions in relation to organic food consumption, while these may play an important role as they may increase involvement and thus help to jolt food purchasers out of their conventional food routine. Also more research related to the role of uncertainty (reduction) in the process of buying organic food would be valuable.

The fifth article of Hoefkens et al (2009b) compares the scientific evidence with knowledge and perception of consumers on organic food. This article reports a part of the results of the consumer survey conducted among Flemish regular and non-regular consumers of organic food. It is found that respondents in general have a positive attitude towards organic food products. Contaminant and nutrient content of organic vegetables are the two major drivers for consumers to believe in the health advantages of organic vegetables. This perception is stronger with increasing consumption frequency, but is independent of gender, residence, education and income level. The results reveal that the positive consumers' perception of organic versus conventional vegetables are based on stereotypes, image transfer and emotion instead of factual knowledge. 
The sixth and last article in this special issue of Mondelaers et al (2009b) analyses the results of the choice experiment included in the survey. This is an interesting technique as it allows to statistically verify the contribution of different attributes consumers use when making choices. Findings reveal that health related traits score better than environmental traits in shaping consumer preference for organic vegetables. Consumers prefer organic products over B-branded products, but not over A-branded products, which suggests that consumers classify organic products among other quality niche products. However, they attribute a better score to the health and environment related quality traits of organic products, indicating a difference in quality cues between organic products and quality products in general. Price becomes less important, whereas presence of an organic label becomes more important with increasing buying intensity of organic vegetables. Undesirable traits, such as pesticide residue levels, trigger a stronger response than desirable traits, such as environmental or health benefits.

\section{Conclusions}

This special issue presents a comprehensive overview and analysis of peer reviewed scientific results with respect to the differences between conventional and organic farming. Novel is that it analyses both facts and perceptions. As the different contributions show, the existing literature is far from conclusive on environmental and health aspects. For most elements, it is clear that on a per hectare basis organic production puts a lower burden on our environment. However, this difference is much less pronounced when effects are expressed per unit of production, due to the lower efficiency of the organic production system in developed countries. A major challenge for the organic production system is therefore to increase the productivity while maintaining its low environmental impact. With respect to nutrient and contaminant content, scientific evidence so far does not allow hard conclusions in favor of organic products, with exception for their lower pesticide residues content.

This lack of scientific evidence does not prevent consumers to have a positive image of organic production. This positive image emerges from the promotion of organic farming's alternative management practices, which trigger positive expectations concerning environmental benefits and health effects. With the hard evidence being inconclusive, it seems that consumers rely less on a cognitive and more on an affective approach and on emotions when forming their attitudes towards organic food consumption. Present research on these topics is still limited and deserves more attention, in particular because it presents a certain vulnerability for the organic market segment.

During the food purchasing process, the potential buyer opposes the perceived value difference to the price difference. A positive attitude is therefore not enough to guarantee a purchase. As reported by Aertsens et al. (2009) there remains an important gap between a positive attitude towards organic food and a low adoption of it. The majority of consumers thus seems to question the 'value for money' or finds that the barriers for purchasing organic food are still too high. The analyses reported in this issue allow to derive major elements explaining differences in attitudes among non- or occasional and heavy users and points to the major barriers for purchasing organic products. For non- or occasional users price remains a major obstacle, indicating that further efforts are needed to make the organic production and distribution chain more efficient resulting in substantial price decreases.

Although the results presented in this issue must be interpreted with care given the revealed restrictions of the research, we are convinced that they yield useful information for the 
organic sector and all market players involved as they point both to strong and weak issues related to the production and consumption of organic products.

\section{$5 \quad$ References}

Aertsens, J., Verbeke, W., Mondelaers, K. and Van Huylenbroeck, G. (2009), "Personal determinants of organic food consumption: a review", British Food Journal.

De Backer, E., Aertsens, J., Vergucht, S, Steurbaut, W. (2009), "Assessing the ecological soundness of organic and conventional agriculture by means of life cycle assessment (LCA) a case study of leek production", British Food Journal.

Figge, F. and Hahn, T. (2004), "Sustainable Value Added - measuring corporate contributions to sustainability beyond eco-efficiency", Ecological Economics, Vol. 48 (2): 173-87.

Hoefkens, C., Vandekinderen, I, De Meulenaer, B., Devlieghere, F., Baert, K., Sioen, I., De Henauw, S., Verbeke, W., Van Camp, J. (2009a), "A literature-based comparison of nutrient and contaminant contents between organic and conventional vegetables and potato", British Food Journal.

Hoefkens, C., Verbeke, W., Aertsens, J., Mondelaers, K. and Van Camp, J. (2009b), "The nutritional and toxicological value of organic vegetables: consumer perception versus scientific evidence", British Food Journal

Mondelaers, K., Aertsens, J., Van Huylenbroeck, G. (2009a), "A meta-analysis of the differences in environmental impacts between organic and conventional farming", British Food Journal.

Mondelaers, K., Verbeke, W., Van Huylenbroeck, G. (2009b), "Importance of health and environment as quality traits in the buying decision of organic products", British Food Journal.

Organic Centre Wales (2004). Organic Food: Understanding the consumer and increasing sales. Taylor Nelson Sofres. T. W. D. Agency, O. C. Wales and S. Association. Aberystwyth, UK: 45.

Padel, S. and Foster, C. (2005), "Exploring the gap between attitudes and behaviour Understanding why consumers buy or do not buy organic food", British Food Journal 107(8): 606-625. 